\title{
Facile Synthesis and Special Phase Transformation of Hydrophilic Iron Oxides Nanoparticles
}

\author{
Liqiao Chen, Yunqian Long, Zhe Leng, Jinfei Hu, Xuan Yu, and Xiaoming Yu
}

Innovation \& Application Institute, Zhejiang Ocean University, Zhoushan, Zhejiang 316004, China

Correspondence should be addressed to Xiaoming Yu; yuxmzjou@163.com

Received 10 October 2017; Accepted 2 November 2017; Published 23 November 2017

Academic Editor: Paulo Cesar Morais

Copyright (C) 2017 Liqiao Chen et al. This is an open access article distributed under the Creative Commons Attribution License, which permits unrestricted use, distribution, and reproduction in any medium, provided the original work is properly cited.

\begin{abstract}
Superparamagnetic iron oxide nanoparticles (SPIONs), $\gamma-\mathrm{Fe}_{2} \mathrm{O}_{3}$, with hydrophilic surfaces are fabricated in ethylene glycol solutions, without surfactant or additive, by solvothermal process from $\alpha-\mathrm{Fe}_{2} \mathrm{O}_{3}$ nanoparticle as precursors. With the addition of a trace of hydrazine hydrate, the cubic phase $\mathrm{Fe}_{3} \mathrm{O}_{4}$ nanoparticles are obtained instead of $\gamma-\mathrm{Fe}_{2} \mathrm{O}_{3}$. The saturation magnetization value of $\gamma-\mathrm{Fe}_{2} \mathrm{O}_{3}$ nanoparticles is up to $74.3 \mathrm{emu} / \mathrm{g}$. This study provides a low cost, safe, and universal route to serve as excellent biocompatibility magnetic core for future applications in biomedical, agriculture, and horticulture applications.
\end{abstract}

\section{Introduction}

Superparamagnetic iron oxide nanoparticles (SPIONs) attracted increasing attention due to their promising applications like tissue cryopreservation, magnetic resonance imaging (MRI), immunoassay, biomolecule separation, hyperthermia, and drug delivery [1-4]. All of these biomedical applications require the nanoparticles to have high magnetization values and hydrophilic surface and also nontoxicity and biocompatibility $[5,6]$.

Until now, various wet chemical processes such as coprecipitation, sol-gel, hydrothermal/solvothermal, thermal decomposition, electrochemical strategy, and ultrasonic chemistry have been extensively applied to prepare superparamagnetic nanoparticles [7-10]. Among these routes, different surfactants, such as oleic acid, are introduced to prevent the aggregation of nanoparticles; also toxic reagents such as $\mathrm{Fe}(\mathrm{III})$ glucuronate, $\mathrm{Fe}(\mathrm{acac})_{3}$, or $\mathrm{Fe}(\mathrm{CO})_{5}$ are usually used, which render the surface of as-obtained samples to be nonbiocompatible, and obstructed the further surface modification $[4,8,11,12]$.

Benefiting from previous study [13], we find a novel route to synthesize superparamagnetic iron oxide nanoparticles through $\alpha-\mathrm{Fe}_{2} \mathrm{O}_{3}$ nanoparticles as precursor in this study, only in presence of ethylene glycol, without the presence of any other agents, surfactants, and additives. Herein, nanoscale $\gamma-\mathrm{Fe}_{2} \mathrm{O}_{3}$ particles were obtained using a smaller particle size of $\alpha-\mathrm{Fe}_{2} \mathrm{O}_{3}$ as precursors and the mild ethylene glycol as a solvent. This study provides excellent biocompatibility magnetic core for applications in biomedical, agriculture, and horticulture applications.

\section{Experimental}

$\alpha-\mathrm{Fe}_{2} \mathrm{O}_{3}$ precursors were synthesized by the modified solvothermal method as previously reported [13]: $0.273 \mathrm{~g}$ of $\mathrm{FeCl}_{3} \cdot 6 \mathrm{H}_{2} \mathrm{O}(0.1 \mathrm{mmol})$ was dissolved under vigorous magnetic stirring in ethanol $(10.0 \mathrm{~mL})$ and $2 \mathrm{~mL}$ of deionized water. Until completely dissolved, $0.6 \mathrm{~g}$ of sodium acetate was added while stirring. The mixture was sealed in a Teflonlined stainless-steel autoclave $(25 \mathrm{~mL})$ and maintained at $160^{\circ} \mathrm{C}$ for $3 \mathrm{~h}$ for solvothermal crystallization. $\gamma-\mathrm{Fe}_{2} \mathrm{O}_{3}$ nanoparticles were synthesized by the following procedure: the samples were washed by distilled water and absolute ethanol then transferred to a Teflon-lined stainless-steel autoclave $(25 \mathrm{~mL})$ and sealed after adding $10 \mathrm{~mL}$ of ethylene glycol, and solvothermal processing was maintained at $180^{\circ} \mathrm{C}$ for $12 \mathrm{~h}$. The resulting products were washed with water and alcohol several times and finally dried in a desiccator at $60^{\circ} \mathrm{C}$ for ca. $10 \mathrm{~h}$.

Powder X-ray diffraction (XRD) was characterized by a Rigaku D/MAX 2200 diffractometer. Scanning electron microscopy (SEM) was taken with a FEI Quanta 400. TEM images were prepared on a JEM-2010HR transmission 


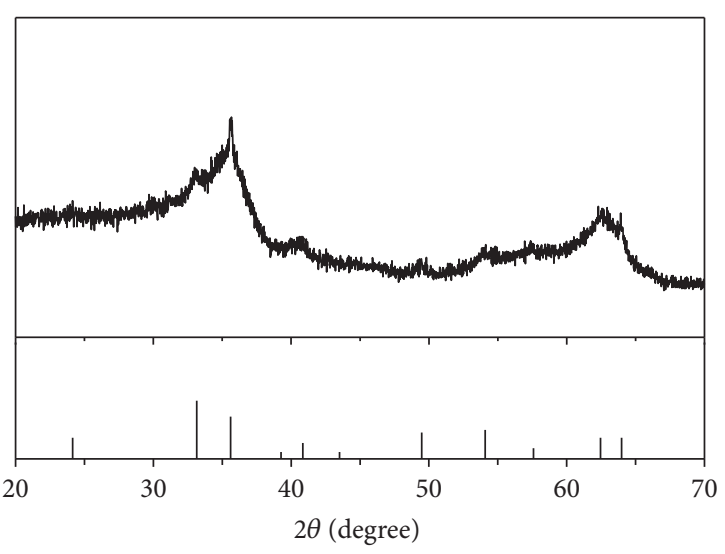

(a)

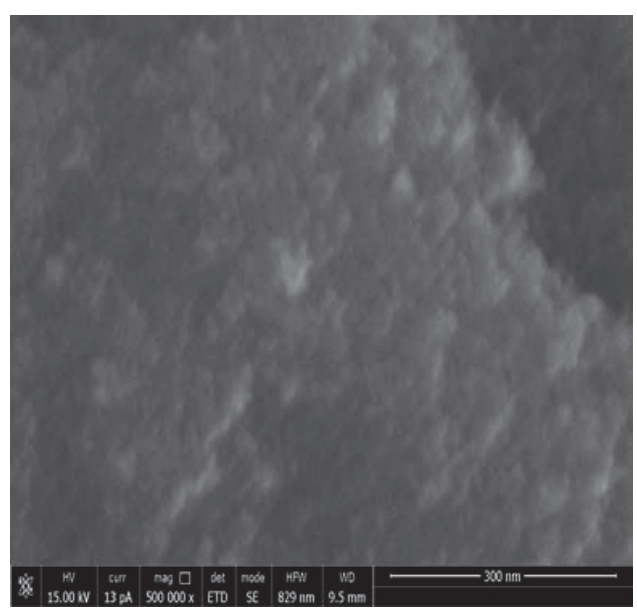

(c)

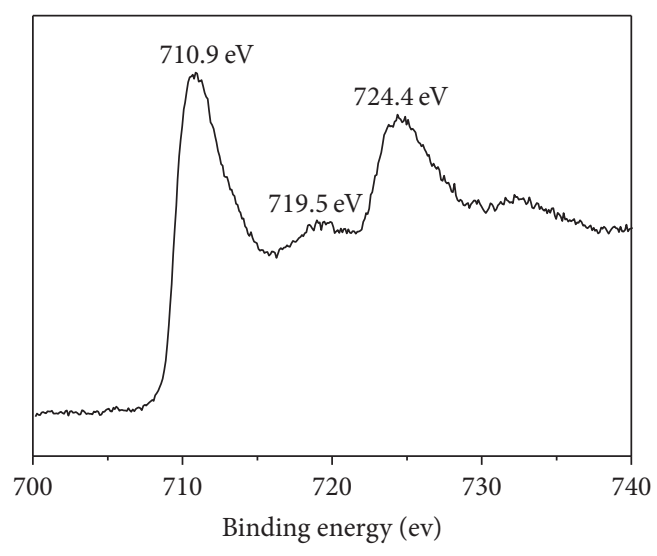

(b)

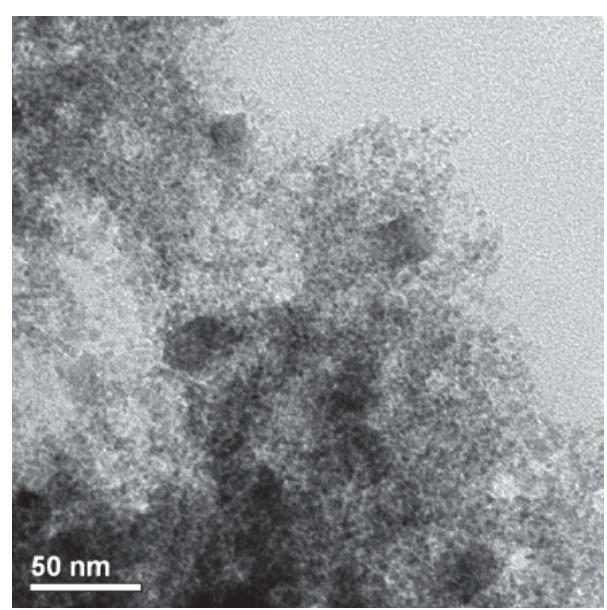

(d)

Figure 1: pXRD (a), Fe 2p XPS (b), SEM (c), and TEM (d) of the as-prepared $\alpha-\mathrm{Fe}_{2} \mathrm{O}_{3}$ precursors.

electron microscope. X-ray photoelectron spectra (XPS) were recorded on an ESCALAB 250 spectrometer. The magnetic properties of the samples were measured at $300 \mathrm{~K}$ on a Quantum Design MPMS XL-7 SQUID magnetometer.

\section{Results and Discussion}

The powder X-ray diffraction patterns (pXRD) of as-prepared $\alpha$ - $\mathrm{Fe}_{2} \mathrm{O}_{3}$ precursor in Figure 1(a) match with JCPDS card number 33-0664 for rhombohedral $\alpha-\mathrm{Fe}_{2} \mathrm{O}_{3}$ with $a=b=$ $0.5036 \mathrm{~nm}$ and $c=1.3749 \mathrm{~nm}$, confirming that the product is hematite. The weak peaks of XRD patterns probably foretold a very small crystal size or amorphous state of the final products. Figure 1(b) shows the XPS spectrum of as-prepared nanoparticles. The $\mathrm{Fe}_{2 \mathrm{p}} 3 / 2$ binding energy of $710.9 \mathrm{eV}$ and the corresponding satellite peak at $719.5 \mathrm{eV}$, a result of charge transfer screening, can be solely attributed to the presence of $\mathrm{Fe}^{3+}$ of the solid samples, indicating that the as-synthesized sample is composed of $\alpha-\mathrm{Fe}_{2} \mathrm{O}_{3}$ [14]. From the SEM and TEM image in Figures 1(c) and 1(d), we could see that the sample consists of nanoparticles with sizes of only less than $3 \mathrm{~nm}$, which are greatly less than $\alpha-\mathrm{Fe}_{2} \mathrm{O}_{3}$ in our previous work [13].
Then, the new structure were obtained by adding $10 \mathrm{~mL}$ of ethylene glycol into as-prepared $\alpha-\mathrm{Fe}_{2} \mathrm{O}_{3}$ precursors, and solvothermal processing was maintained at $180^{\circ} \mathrm{C}$ for $12 \mathrm{~h}$. The pXRD of as-synthesized typical sample in Figure 2(a) match well with JCPDS card number 39-1346 for cubicstructure iron oxide with $a=b=c=8.395 \mathrm{~nm}$. However, it is difficult to distinguish the $\gamma-\mathrm{Fe}_{2} \mathrm{O}_{3}$ and $\mathrm{Fe}_{3} \mathrm{O}_{4}$ phases only from the XRD patterns due to their similarity of phase structures. The XPS spectrum is usually an important way to distinguish $\gamma-\mathrm{Fe}_{2} \mathrm{O}_{3}$ and $\mathrm{Fe}_{3} \mathrm{O}_{4}$ phase. The powder samples (Figure 2(b)) are similar to that of $\alpha-\mathrm{Fe}_{2} \mathrm{O}_{3}$ precursors, and the satellite peak at $719.6 \mathrm{eV}$ still exists, indicating that the assynthesized sample is composed of $\gamma-\mathrm{Fe}_{2} \mathrm{O}_{3}$. The atom ratio of the product is determined as $\mathrm{Fe}(23.99 \%)$ and $\mathrm{O}(56.54 \%)$ using XPS analysis. The oxygen content is higher than that of both $\mathrm{Fe}_{3} \mathrm{O}_{4}$ and $\gamma-\mathrm{Fe}_{2} \mathrm{O}_{3}$. On one hand, it is probably because oxygen atoms are as the terminal atom layer for iron oxide crystals, which results in a higher oxygen detecting value near the crystals surfaces; on the other hand, the clean surfaces easily adsorb oxygen in the air.

From the TEM image in Figure 2(c), we can see that the product consists of highly dispersed polyhedral nanoparticles 


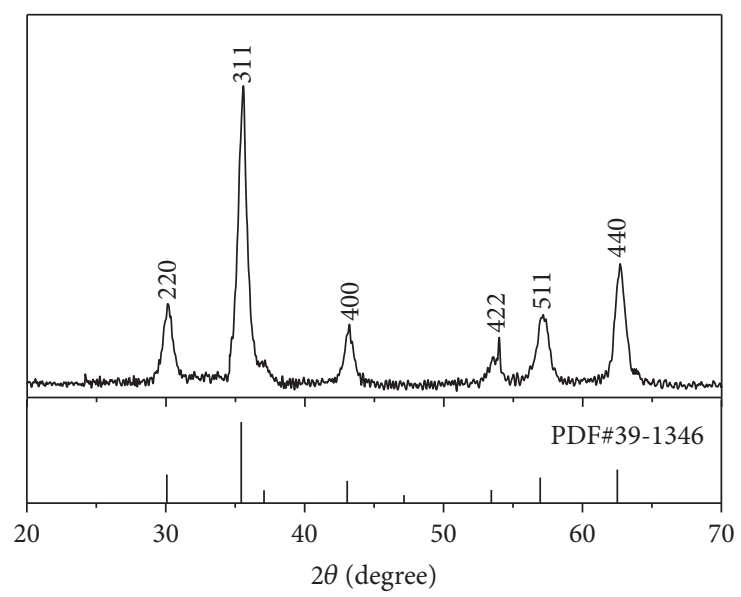

(a)

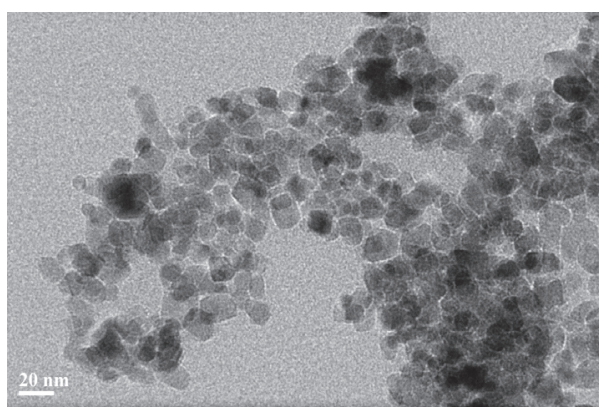

(c)

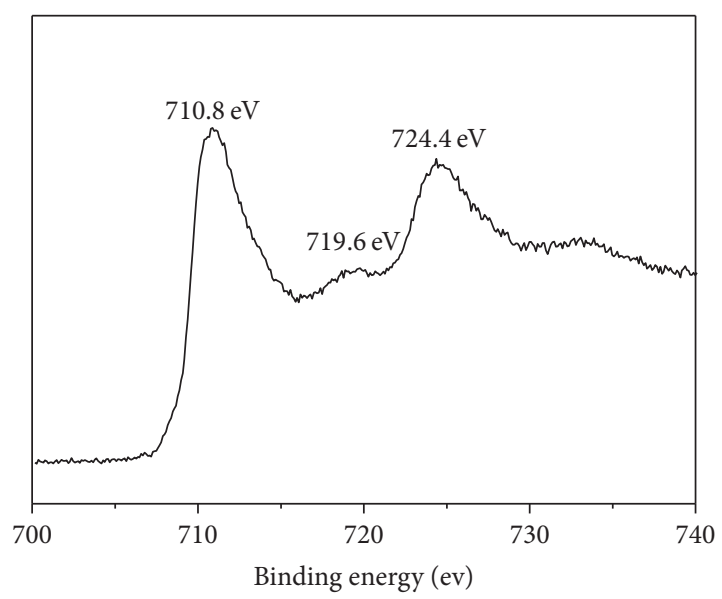

(b)

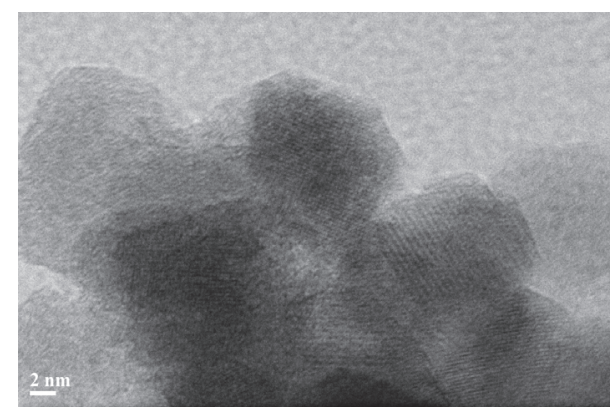

(d)

Figure 2: pXRD (a), Fe 2p XPS (b), TEM (c), and HRTEM (d) of the as-obtained $\gamma$ - $\mathrm{Fe}_{2} \mathrm{O}_{3}$ nanoparticles.

and the sizes of particles are about $18 \mathrm{~nm}$ with narrow size distribution. The clear lattice fringes of nanoparticles in the high-resolution transmission electron microscopy (HRTEM) show the as-obtained powders with high crystallinity (Figure $2(\mathrm{~d})$ ).

In our previous report, the side surface edges $\alpha-\mathrm{Fe}_{2} \mathrm{O}_{3}$ nanoplates gradually redissolved into nanoparticles through "a mass transformation" during solvothermal processing [13]. We could speculated that other iron oxides particles should be obtained if we tune some experimental conditions during "a mass transformation." Herein, nanoscale $\gamma-\mathrm{Fe}_{2} \mathrm{O}_{3}$ was synthesized by using less than $3 \mathrm{~nm}$ or amorphous $\alpha-\mathrm{Fe}_{2} \mathrm{O}_{3}$ as precursor in present of ethylene glycol.

However, if a trace of hydrazine hydrate was brought, the cubic phase $\mathrm{Fe}_{3} \mathrm{O}_{4}$ nanoparticles are obtained instead of $\gamma-\mathrm{Fe}_{2} \mathrm{O}_{3}$. We believe that the possible "intermediate" phase $\mathrm{Fe}_{3} \mathrm{O}_{4}$ forms during regrowth of $\gamma-\mathrm{Fe}_{2} \mathrm{O}_{3}$ or $\mathrm{Fe}_{3} \mathrm{O}_{4}$ crystals from $\alpha-\mathrm{Fe}_{2} \mathrm{O}_{3}$ precursors, but the "intermediate" is unstable and fast converts into $\gamma-\mathrm{Fe}_{2} \mathrm{O}_{3}$ under the condition of high temperature and rich-oxygen [15]. If hydrazine hydrate is used at the same experiment conditions, the "intermediate" is maintained due to the strong reducing atmosphere, resulting in the final products of cubic $\mathrm{Fe}_{3} \mathrm{O}_{4}$ (Figure 3(a)); however, sizes of the products are still nanoscale (Figure 3(b)). Therefore, we can speculate that the reducing atmosphere in the hydrothermal system determines the final phase of the iron oxides.

Finally, the magnetic characteristics of the prepared nanoparticles in the presence of magnetic field were measured using a vibrating sample magnetometer (VSM). Figure 4 (a) shows the hysteresis loops at $300 \mathrm{~K}$ of as-prepared $\alpha-\mathrm{Fe}_{2} \mathrm{O}_{3}$ precursor. It can be found that the saturation magnetization (Ms), remanent magnetization ( $\mathrm{Mr}$ ), and coercivity $(\mathrm{Hc})$ are $13.6 \mathrm{emu} / \mathrm{g}, 0.016 \mathrm{emu} / \mathrm{g}$ and $92.6 \mathrm{Oe}$, respectively, showing soft ferromagnetic behaviour. Accordingly, the three values of as-synthesized $\gamma-\mathrm{Fe}_{2} \mathrm{O}_{3}$ nanoparticles are $74.3 \mathrm{emu} / \mathrm{g}, 2.86 \mathrm{emu} / \mathrm{g}$, and $43 \mathrm{Oe}$, respectively. The low remanent magnetization and high saturation magnetization simply indicate that the as-synthesized $\gamma-\mathrm{Fe}_{2} \mathrm{O}_{3}$ nanoparticles are with good superparamagnetic property [9].

\section{Conclusions}

Our work offers a facile method to prepare biocompatible nanoparticles. Herein, we adopted $\alpha-\mathrm{Fe}_{2} \mathrm{O}_{3}$ as precursor to realize the growth of $\gamma-\mathrm{Fe}_{2} \mathrm{O}_{3}$ nanoparticles, and $\mathrm{Fe}_{3} \mathrm{O}_{4}$ nanoparticles can also be obtained only with the addition of a trace of hydrazine hydrate. The as-obtained samples are dispersed in water with a clean surface. This route provides a practical method to controllably prepare high quality iron oxides 


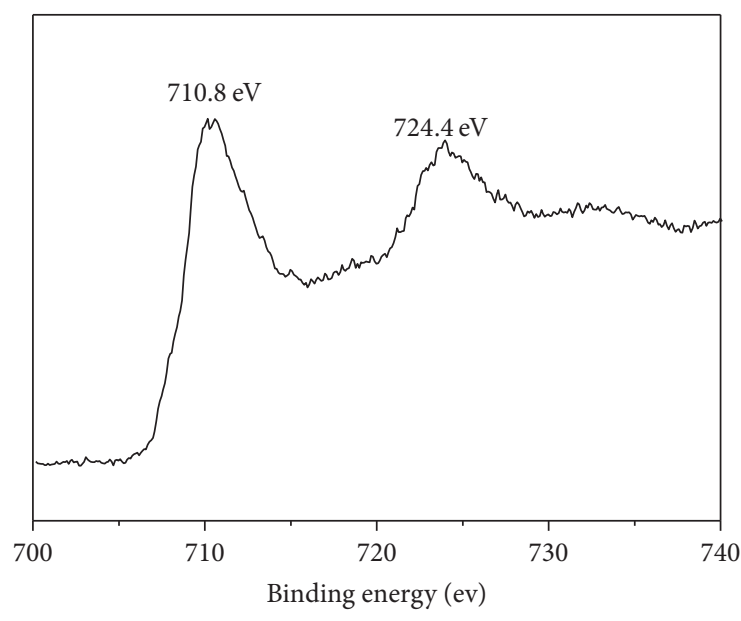

(a)

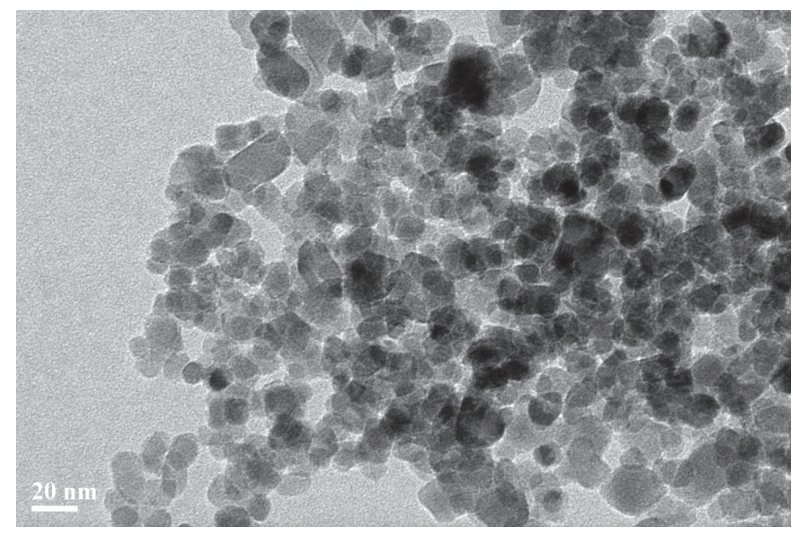

(b)

FIgURE 3: XPS (a) and TEM images (b) of the $\mathrm{Fe}_{3} \mathrm{O}_{4}$ polyhedrons obtained with the addition of a trace of hydrazine hydrate.

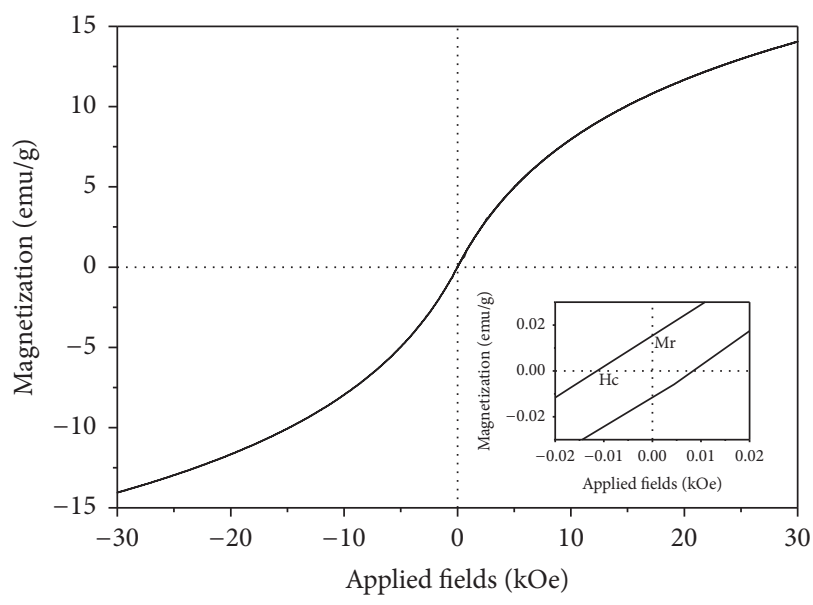

(a)

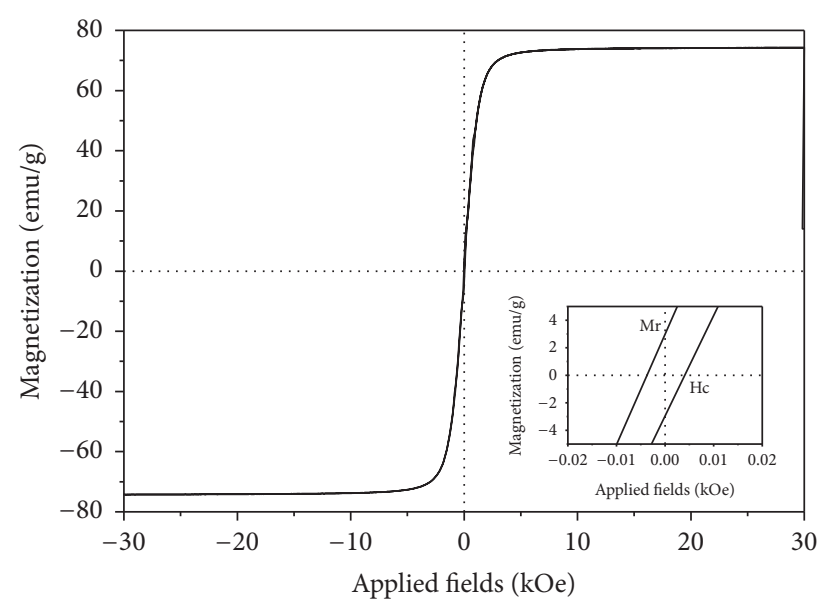

(b)

FIGURE 4: Magnetization-hysteresis (M-H) loops of $\alpha-\mathrm{Fe}_{2} \mathrm{O}_{3}$ precursors (a) and as-obtained $\gamma$ - $\mathrm{Fe}_{2} \mathrm{O}_{3}$ samples (b); the inset is the enlarged ones in the range of -0.02 and $0.02 \mathrm{KOe}$.

for biomedical application. The magnetic measurement by VSM revealed that the prepared iron oxides exhibit excellent superparamagnetic behavior.

\section{Conflicts of Interest}

The authors declare that they have no conflicts of interest.

\section{Acknowledgments}

This work was supported by the National Natural Science Foundation of China (Grant nos. 51261008 and 11604298) and Scientific Research Foundation of Zhejiang Ocean University (Q1444, 1446, and 1539).

\section{References}

[1] N. Manuchehrabadi, Z. Gao, J. Zhang et al., "Improved tissue cryopreservation using inductive heating of magnetic nanoparticles," Science Translational Medicine, vol. 9, no. 379, Article ID eaah4586, 2017.

[2] Y. Hu, J. Li, J. Yang et al., "Facile synthesis of RGD peptidemodified iron oxide nanoparticles with ultrahigh relaxivity for targeted MR imaging of tumors," Biomaterials Science, vol. 3, no. 5, pp. 721-732, 2015.

[3] F. M. Kievit, O. Veiseh, N. Bhattarai et al., "PEI-PEG-chitosancopolymer-coated iron oxide nanoparticles for safe gene delivery: synthesis, complexation, and transfection," Advanced Functional Materials, vol. 19, no. 14, pp. 2244-2251, 2009. 
[4] W. Zhang, X. Liu, X. Zhao, and X. Zhang, "Controllable delivery of peptides by superparamagnetic $\mathrm{Fe}_{3} \mathrm{O}_{4}$ /slica nanoparticle vehicles," Materials Letters, vol. 201, pp. 177-180, 2017.

[5] B. Alqasem, N. Yahya, S. Qureshi, M. Irfan, Z. Ur Rehman, and $\mathrm{H}$. Soleimani, "The enhancement of the magnetic properties of $\alpha-\mathrm{Fe}_{2} \mathrm{O}_{3}$ nanocatalyst using an external magnetic field for the production of green ammonia," Materials Science and Engineering: B Advanced Functional Solid-State Materials, vol. 217, pp. 49-62, 2017.

[6] H. Cai, A. Xiao, J. Cui et al., "Facile hydrothermal synthesis and surface functionalization of polyethyleneimine-coated iron oxide nanoparticles for biomedical applications," ACS Applied Materials \& Interfaces, vol. 5, no. 5, pp. 1722-1731, 2013.

[7] D. Han, S. Yang, J. Yang et al., "Synthesis of $\mathrm{Fe}_{3} \mathrm{O}_{4}$ nanoparticles via chemical coprecipitation method: modification of surface with sodium dodecyl sulfate and biocompatibility study," Nanoscience and Nanotechnology Letters, vol. 8, no. 4, pp. 335-339, 2016.

[8] V. Patsula, L. Kosinová, M. Lovrić et al., "Superparamagnetic $\mathrm{Fe}_{3} \mathrm{O}_{4}$ Nanoparticles: synthesis by thermal decomposition of Iron(III) glucuronate and application in magnetic resonance imaging," ACS Applied Materials \& Interfaces, vol. 8, no. 11, pp. 7238-7247, 2016.

[9] I. Karimzadeh, H. R. Dizaji, and M. Aghazadeh, "Development of a facile and effective electrochemical strategy for preparation of iron oxides $\left(\mathrm{Fe}_{3} \mathrm{O}_{4}\right.$ and $\left.\gamma-\mathrm{Fe}_{2} \mathrm{O}_{3}\right)$ nanoparticles from aqueous and ethanol mediums and in situ PVC coating of $\mathrm{Fe}_{3} \mathrm{O}_{4}$ superparamagnetic nanoparticles for biomedical applications," Journal of Magnetism and Magnetic Materials, vol. 416, pp. 81-88, 2016.

[10] M. Beriache, N. A. C. Sidik, M. N. A. W. M. Yazid, R. Mamat, G. Najafi, and G. H. R. Kefayati, "A review on why researchers apply external magnetic field on nanofluids," International Communications in Heat and Mass Transfer, vol. 78, pp. 60-67, 2016.

[11] A. L. Kholmetskii, S. A. Vorobyova, A. I. Lesnikovich, V. V. Mushinskii, and N. S. Sobal, "A novel route for the preparation of magnetic fluids," Materials Letters, vol. 59, no. 16, pp. 19931996, 2005.

[12] B. Zhang, Z. Tu, F. Zhao, and J. Wang, "Superparamagnetic iron oxide nanoparticles prepared by using an improved polyol method," Applied Surface Science, vol. 266, pp. 375-379, 2013.

[13] L. Chen, X. Yang, J. Chen et al., "Continuous shape- and spectroscopy-tuning of hematite nanocrystals," Inorganic Chemistry, vol. 49, no. 18, pp. 8411-8420, 2010.

[14] J. Lu, X. Jiao, D. Chen, and W. Li, "Solvothermal Synthesis and Characterization of $\mathrm{Fe}_{3} \mathrm{O}_{4}$ and $\gamma$ - $\mathrm{Fe}_{2} \mathrm{O}_{3}$ Nanoplates," The Journal of Physical Chemistry C, vol. 113, no. 10, pp. 4012-4017, 2009.

[15] G. Zhao, C. Wu, and M. Yan, "Enhanced magnetic properties of Fe soft magnetic composites by surface oxidation," Journal of Magnetism and Magnetic Materials, vol. 399, pp. 51-57, 2016. 

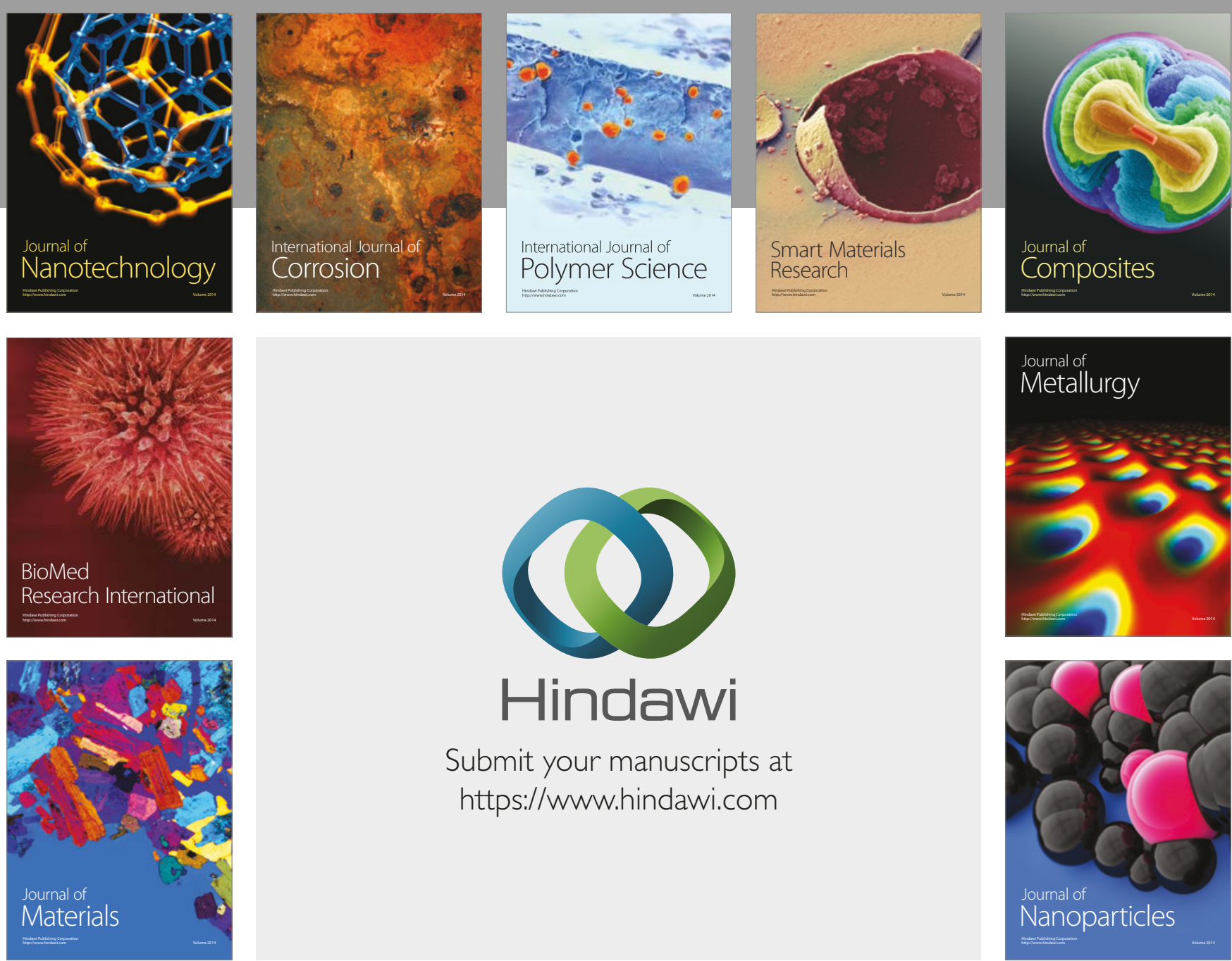

\section{Hindawi}

Submit your manuscripts at

https://www.hindawi.com
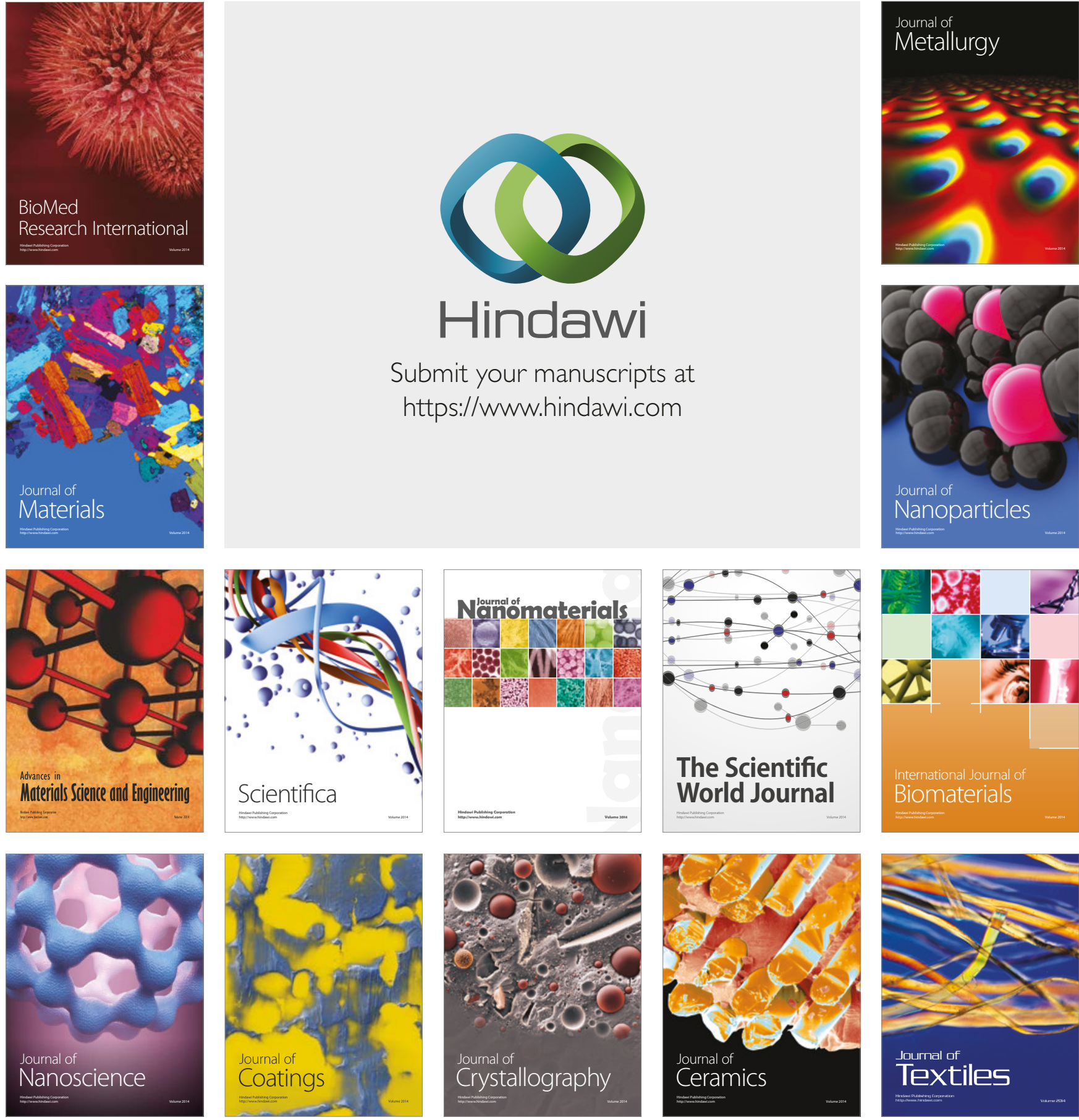

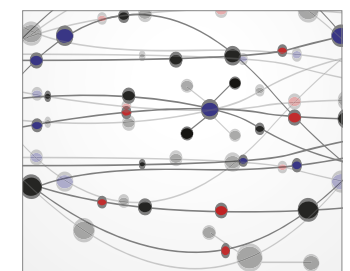

The Scientific World Journal
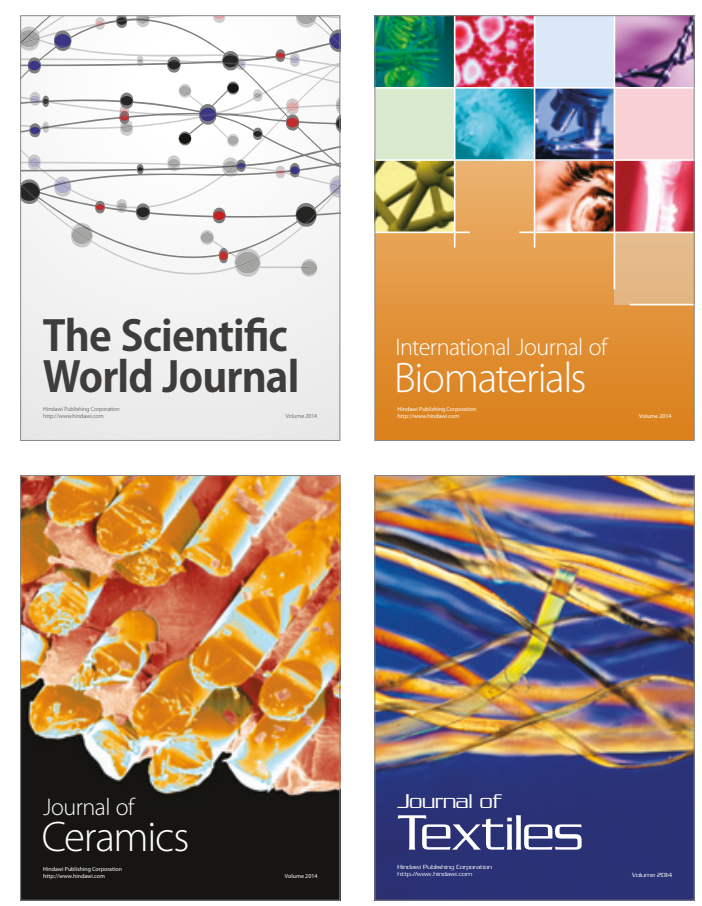